\title{
The "Queen Bee Syndrome" in Sports Federations: An Exploratory Investigation of Gender Stereotypes in Italian Female Coaches
}

\author{
Caterina Cibibin and Irene Leo *(i)
}

Citation: Cibibin, C.; Leo, I. The "Queen Bee Syndrome" in Sports Federations: An Exploratory Investigation of Gender Stereotypes in Italian Female Coaches. Sustainability 2022, 14, 1596 https://doi.org/10.3390/su14031596 Academic Editors: Stefano Boca and Ambra Gentile

Received: 16 December 2021

Accepted: 25 January 2022

Published: 29 January 2022

Publisher's Note: MDPI stays neutral with regard to jurisdictional claims in published maps and institutional affiliations.

Copyright: (C) 2022 by the authors. Licensee MDPI, Basel, Switzerland. This article is an open access article distributed under the terms and conditions of the Creative Commons Attribution (CC BY) license (https:// creativecommons.org/licenses/by/ $4.0 /)$.
Department of Developmental Psychology and Socialization, University of Padova, 35131 Padova, Italy; caterina.cibibin@gmail.com

* Correspondence: irene.leo@unipd.it

\begin{abstract}
Several studies have shown that women in top positions tend to hinder and mistreat other women; this phenomenon is known in the literature under the term "Queen bee syndrome". The aim of this study is to investigate whether Queen bee syndrome is also present within the Italian Sports Federations. To this end, an online questionnaire was administered to Italian female coaches $(n=516)$. From the statistical analyses, it emerged that coaches in the $40-49$ age group attribute to themselves more masculine than feminine adjectives (Bem Sex-Role Inventory, BSRI), and also score higher on the gender stereotype scales, the Attitudes Towards Women Scale $(d=-0.1189, p<0.05)$ and the Macho Scale, compared to trainers in the 18-29 age group $(d=-0.1681, p<0.05)$. Moreover, a positive correlation emerges between the scores obtained on the Attitudes Towards Women Scale and Macho Scale $(r=0.600, p<0.01)$ and between organizational support and affective attachment to the organization $(r=0.529, p<0.01)$. Overall, all the results seem to show the presence of the Queen bee syndrome within the Italian Sports Federations. In the future, it will be interesting to evaluate additional variables involved in this phenomenon.
\end{abstract}

Keywords: Queen bee syndrome; gender stereotypes; sports federations

\section{Introduction}

Several studies have shown that women who achieve leadership roles in male-dominated environments are more likely to endorse gender stereotypes. That is, they tend to hinder rather than support the growth of their female subordinates and possess negative attitudes toward them [1,2]. The term "Queen bee syndrome", originally invented by Travis [3], was used to describe the phenomenon according to which senior women are keen on supporting the structural hierarchy that allowed them to achieve success $[3,4]$. The Queen bee phenomenon has been described in response to a threat to social identity, meaning the development of the personality of human beings through the groups to which they belong [5].

In a corporate culture marked by centuries of male predominance, women's emancipation does not easily fit in. From the very beginning, the working sphere has been a matter reserved solely for men; in fact, one of the criteria on which the differences between the genders are based, and which bind the values of male and female roles, is precisely the division of work and tasks [6].

According to the social theory of gender roles, within society, people are assigned roles with a different status depending on their gender. In this hierarchical structure, men are assigned roles with a higher status. This difference influences the stereotypes determined for men and women, as well as the behaviors and expectations of both genders. Change in gender differences will occur when male and female roles enforce equitable sharing in the division of labor and tasks [7-9]. 
Although an increase in the presence of women in public working environments has been observed in recent years, the same trend has not been observed in management positions. Companies in which women occupy the highest positions are rare: boards of directors with a female majority, or those consisting of women only, represent a small minority in the realm of corporations operating in Italy [10]. A possible explanation for why women find it difficult to attain positions of power may be found in the correlation between power and authority and masculinity, which makes it difficult for women to identify their female gender with a more male "power" identity [11]. As behaviors in the working environments tend to be masculine, women have to negotiate masculine norms that often exclude them, so they end up hiding their femininity in order to live up to the masculine ideal; this is how women begin to lose themselves [12]. In order to adhere to the norms of organizational culture, women begin to act like men, denying their own gender and consequently all those peculiarities that make them different.

People who fit the prototype are more likely to be accepted, included and advanced into leadership positions, which further reinforces the one-size-fits-all standard of success [12].

The leadership role is characterized by a predominance of the agency component over the communality component, i.e., it is defined by task performance rather than the relational component, and is stereotyped as masculine [13]. The characteristics that are required of an excellent manager are strong self-esteem, task orientation, and commitment to objectives; all dimensions belonging to the agency component.

On the contrary, women are associated with characteristics such as emotional warmth, empathy, care, kindness and understanding, and thus the stereotype assumes that they give priority to others and have an orientation towards relational components [13]. This division of skills has an impact on judgments when one gender tests itself in terms of abilities defined as typical for the other: it has been measured that those men who demonstrate communal traits are evaluated much more positively than women who demonstrate agency-driven attitudes, the former being considered more "complete" and the latter being negatively considered "masculine", and therefore out of role $[13,14]$.

Women are forced to adapt to the masculine culture that pervades the organization in order to reach senior positions, but when they adopt behaviors and attitudes typically reserved for men, they are perceived as deviating from the role they have been given by society: there seems to be no escape. Research on the backlash effect [15] has found that women who are successful in tasks traditionally perceived as masculine are classified as disliked by both men and women themselves. This backlash occurs because successful women violate descriptive and prescriptive gender norms and are assumed to lack feminine traits, such as warmth [15,16]. Indeed, the "price of adherence" [17] for women in traditional executive culture is the silence required for compliance with masculine norms and criteria. What becomes clear is that women's presence in a man's world is conditioned by their willingness to modify their behavior to become more like men, or be perceived as more masculine than men [18].

The Queen bee phenomenon is the result of social circumstances related to the threat to social identity that women face in companies that discriminate against them: the tension between women's personal ambitions and the gender stereotypes expressed around them creates a threat to their social identity [19]. Acting like a Queen bee is, for these women, a way of pursuing their ambitions in sexist organizational cultures.

Women working in corporations where the cultural structure depicts them as less fit to reach professional success compared to men, thus degrading their gender, experience this as a threat to their social identity [20]. In order to reduce this uncomfortable situation, women may start to behave in a way that leads to an improvement of the whole gender status; "collective mobility", for instance, refers to women fighting negative gender stereotypes in order to improve their situation in the working environment or their personal achievements, and "individual mobility" is the behavior of a woman supporting the difference between them and other women in order to enhance their career growth. Moreover, it has been shown that women more keen on identifying themselves with their gender tend to be more 
loyal to the group, and work towards a better reputation for the collective when this is threatened; on the other hand, people that do not identify themselves with their gender tend to move away from the group and work towards the improvement of their own, individual, situation $[21,22]$. The Queen bee syndrome is thus the result of some social circumstances mainly caused by the threatening of women's social identity by the corporations that discriminate against them [4]. The tension between women's own ambitions and the gender stereotypes developed around them endangers their social identity, in particular in people for whom the gender identity is not relevant for the realization of themselves in that specific context [19]. To behave as a Queen bee is, for those women, one of the possible ways to pursue their goals and ambitions in the sexist hierarchical cultures and environments [2].

In Ely's ethnography [23] on women lawyers, it has been shown that, comparing women working in companies with a higher percentage of female partners with others working in companies with a lower one, those latter show more competitive relationships between women who, in turn, show a lower probability of perceiving their female partner as supportive. This happens as women have increasing difficulty in finding a woman mentor or a female example to get inspiration from, as the higher the hierarchy gets, the less women we find [3].

Gender-oriented behaviors hold for sports groups as well for companies. The history of sport has always been dominated by men, who still participate in a higher percentage of sport events compared to women [24]. Men's sport leagues and events have always attracted more social and economic interest compared to women [25]. According to Murphy [26], the structure of sport itself encourages an intrinsic mechanism of the society, through its images, ideologies, and structures, which legitimates the differences between sexes, thus reinforcing social stratification based on gender. Whether or not competition is still a duty for young male adults, until the end of the Second World War, physical education and the practice of sport were considered enemies of female standards [27].

Many aspects of sporting activity are often reinterpreted in terms of gender differences [28]. By comparing the available data on men and women coaching in sport, trends can be found whereby women represent a minority of coaches employed in elite sport, and the higher the level of performance, the lower the percentage of female trainers [29,30]. It has been demonstrated that there are many reasons for the lack of female coaches in elite sport. First, in many sports, few women have the necessary licenses to coach elite athletes or teams, and moreover, women aiming to work as high-level trainers face similar problems to women aspiring for leadership positions, e.g., recruitment, stereotyping of their ability, and gender discrimination of tasks [31-33]. Finally, it must also be considered that many training courses required to become a coach are almost exclusively managed by men. Empirical evidence suggests that female coaches are often athletes who have experience at high levels of national and international competition, and they have played in sports more traditionally considered male (i.e., wrestling, baseball) [33]. This aspect allows women to feel more credible and respected, especially when coaching male athletes. Women who coach male athletes may be viewed as less socially acceptable coaches, and often their abilities may be underestimated by athletes and their parents [34].

Besides the role of coaching, it should be noted that women also retain secondary roles in sports institutions: they are often under-represented in management administrative roles, and the top management of the International and National Olympic Committees, as well as the International Sports Federations, are still predominantly male [35]. At an international level, in 1995, the International Olympic Committee (IOC) created the Women in Sport Commission, which aimed to promote the inclusion of women in sport and physical activity. The Olympic Agenda 2020, the strategic roadmap for the Olympic Movement, also reaffirms a commitment to gender balance in sport [36]. Although progress in women's participation in sport, and particularly in elite sport, is undeniable, women's representation in the governance of sports still lags behind. The Women and Sport conference in Sydney in 2010 showed that progress towards having more women in key sport leadership positions 
has remained stagnant. To address this stagnation, the Sydney Scoreboard, a global index tracking women's representation in sport governance and management, was created [36]. Although the number of women on sports governing bodies has visibly increased, it has done so at a slower pace than the number of elite female athletes, and the change remains small [36].

In the Italian sports system, female athletes represent $28.2 \%$, female club managers $15.4 \%$, female coaches below $20 \%$, female federal managers $12.4 \%$, and women judges and referees $18.2 \%$. These percentages that are still too low to consider that gender equality has already been achieved in sport [37].

Considering the similarities between the organizational environments of business and sport, discussed above, in the following study we decided to investigate whether the phenomenon of the Queen bee also occurs within Italian Sports Federations. In the literature, there are no studies that have investigated the phenomenon of the Queen bee in the domain of the Sport Federation. To this end, we examine whether women coaches in Sports Federations: 1 . perceive themselves in a masculine way; 2 . identify with typical male stereotypes, and 3. tend to judge their female colleagues, as well as collaborating less effectively with them.

\section{Materials and Methods}

\subsection{Participants}

Eight-hundred and thirty-one Italian female coaches took part in this study. Of this sample, 315 participants were removed because they did not complete the questionnaire. Thus, the final sample consisted of 516 Italian female coaches (age group from 18-29 to over 50) who completed the questionnaire by answering all questions ( $62 \%$ of completed questionnaires). The questionnaire, which was carefully designed, was sent to all federal sport institution members of the Italian National Olympic Committee (CONI), which then forwarded it to their female coaches for online fulfillment. Participation in the study was voluntary and anonymous. The data collection phase spanned from May 2020 to July 2020, during the first phase of the pandemic related to COVID-19.

\subsection{Instruments}

A questionnaire was used for online data collection, consisting of two parts.

In the first part, each Italian female coach was asked to answer some specific questions about the federations they belonged to (for example, "If Sports Federations had a gender, do you think yours would be male or female?", "Do you think that within the Sports Federation you belong to, there are people who suffer from gender discrimination (i.e., determined by belonging to the female gender)?", "Do you think that your success as a coach is due to effort and hard work or to skills and capabilities?").

Because the phenomenon of the Queen bee syndrome has never been studied within Sports Federations, the second part of the questionnaire used scales that have been used to investigate this phenomenon in other work settings (i.e., University faculty [4]) or other aspects of gender stereotypes [38,39]. In this section of the questionnaire, the female Italian coaches responded to a series of items grouped into 6 measurement scales. The scales used in the study were:

- Gender Identification at Work. This scale is used to measure the degree of gender identification (high or low) at work. Examples of items in this measure are, "At work, being a woman is important to me", and "At work, I feel part of the women's group" (7-point Likert scale from 1 (completely disagree) to 7 (completely agree)) [38];

- Bem Sex-Role Inventory. The BSRI measures masculinity and femininity by assessing how people psychologically identify themselves with gender roles. The test consists of a list of 60 adjectives (20 masculine, 20 feminine and 20 gender-neutral), but in this research only masculine and feminine adjectives were selected, so 40 adjectives were presented. Examples of adjectives are "Autonomous", "Athletic" (more masculine) and "Surrending", "Compassionate" (more feminine). Due to the lack of gender- 
neutrality in Italian grammar, it was decided to include all adjectives in both forms (genders) to prevent that adjective in the masculine form from being perceived by women as reserved for men (7-point Likert scale from 1 (never or almost never true) to 7 (always or almost always true)) [40];

- Attitudes Towards Women Scale (Short version). This is a tool consisting of 25 statements that investigate the attitudes people have towards women's roles in society. A high score indicates that the person answering shows conservative thinking, while a low score indicates a pro-women attitude. Examples of items include "Women should worry less about their rights and more about becoming good wives and mothers", and "Women should take their legitimate place in business and all professions alongside men (reverse item)." (4-point Likert scale: 1 (not at all agree) to 4 (strongly agree)) [41]; Macho Scale. This is a self-report instrument that measures adherence to sexist attitudes. Specifically, through 28 items it assesses individual differences in sex role stereotypes and sex discrimination. High scores reflect more traditional and gender-stereotyped attitudes, and low scores reflect more gender-neutral and feminist attitudes (e.g., equality between men and women). It has been found that high scores on this scale are associated with less pro-women attitudes. Examples of items include "Most of the time it is better to be a man than a woman", "The love of competing and winning is fundamentally a male attitude, although some women have it too" and "A wife who sacrifices her family for her career is no more to blame than a husband who does the same thing (reverse item)." (5-point Likert scale: 0 (strongly agree) to 4 (not at all agree)) [42];

- Survey of Perceived Organizational Support. This scale captures the Perceived Organizational Support (POS), which is a general belief about the degree to which the organization values employee contributions and cares about employee well-being [43] (Italian adaption [12]). The construct concerns the degree to which the organization rewards, empowers, and supports the employee. In this research, by "organization" we mean the institution that plans, promotes, and coordinates the practice of sports in Italy, i.e., all the Sports Federations recognized by the Italian National Olympic Committee (CONI). Examples of items here are "This organization definitely considers my goals and values" and "This organization would forgive a mistake made in good faith on my part." (7-point Likert scale: 1 (not at all) to 7 (very much agree)) [43];

- Organizational Commitment Questionnaire (Affective Component). This scale consists of 25 items that converge into three independent factors corresponding to the three components of the organizational commitment construct-affective commitment, continuance commitment and normative commitment. In this research, only the 10 items concerning the affective component were considered. Allen and Mayer [44] define affective commitment as an emotional attachment to the organization, and when this prevails, employees stay in the organization because they want to. Examples of these items are "Of the different job alternatives available this organization is one of the best to work for" and "I am willing to put in more effort than is normally expected to contribute to the success of my organization." (5-point Likert scale: 1 (not at all agree) to 5 (very much agree)) [44].

As this is meant to be explorative research, we chose to investigate how the Queen bee phenomenon occurs within the sporting environment.

\section{Results}

\subsection{Descriptive Analysis}

The first part of the questionnaire asked the Italian female coaches to answer some demographic questions. The data we collected are as follows: $41.1 \%$ of the women taking part in the survey belong to the age group 18-29, while only $7.8 \%$ are over 50 years old. Women in the age groups $30-39$ and $40-49$ constituted $28.1 \%$ and $23.1 \%$, respectively. Most of the women stated that they were single $(48.1 \%)$ or married/living with their partner $(47.9 \%)$, while only $3.5 \%$ of the participants were separated/divorced. Concerning the 
number of children, $66.5 \%$ of the women reported they had no children, while $15.7 \%$ and $15.5 \%$ stated one child and two children, respectively. Only $1.9 \%$ said they had three or more children. Regarding the Sport Federations they belong to, the coaches who answered the questionnaire belonged to 11 different federations: Italian Cycling Federation (FCI), Italian Gymnastics Federation (FGdI), Italian Baseball Softball Federation (FIBS), Italian Hockey and Skating Federation (FIHP), Italian Swimming Federation (FIN), Italian Volleyball Federation (FIPAV), Italian Rugby Federation (FIR), Italian Equestrian Sports Federation (FISE), Italian Winter Sports Federation (FISI), Italian Tennis Federation (FIT) and Italian Sailing Federation (FIV). Just over half of the respondents belong to FIHP (54.8\%), followed by $17.4 \%$ to FISI, $13 \%$ to FIBS and $11.8 \%$ to FIR. From the Equestrian Sport, Tennis and Sailing Federations, only one coach per federation fully answered the questionnaire.

The last two questions were about how many years they have been coaching, and if this profession was the only job they had or if there were others. The range of answers ranges from a minimum of 1 year to a maximum of 50 years, and the average falls around 11 years $(\mathrm{M}=10.91)$, but the data are very broadly distributed, as the standard deviation is 9.71. The median falls around $7 / 8$ years. Furthermore, $70.3 \%$ of the people attending the survey answered that they have an additional profession in parallel to coaching.

\subsection{Data Analysis}

For data analysis, the SPSS software was used. Cronbach's alpha indicated good homogeneity of scales. Gender Identification at Work: Cronbach's alpha $\alpha=0.75$. Bem Sex-Role Inventory, feminine adjectives: Cronbach's alpha $\alpha=0.78$; masculine adjectives: Cronbach's alpha $\alpha=0.83$. Attitudes Towards Women Scale: Cronbach's alpha $\alpha=0.77$. Macho Scale: Cronbach's alpha $\alpha=0.76$. Survey of Perceived Organizational Support, Italian adaption: Cronbach's alpha $\alpha=0.86$. Organizational Commitment Questionnaire (Affective Component): Cronbach's alpha $\alpha=0.85$.

Chi-square tests were performed in the case of nominal variables, while the other data were obtained through the calculation of correlations.

In each age group, male attributions are greater than female attributions, and the effect of age groups is significant for both the ATWS scale $(p<0.05)$ and the Macho Scale $(p<0.05)$. Specifically, participants belonging to the 40-49 age group obtained higher scores on the ATWS scale than female coaches in the 18-29 range, with a significant difference $(d=-0.1189, p<0.05)$. The pattern is the same for the other scale: the significant gap is between the 18-29 and 40-49 ranges $(d=-0.1681, p<0.05)$; those who belong to the higher range show higher scores on the Macho Scale.

A positive correlation has been found between the years of work and the masculine adjectives of the BSRI, which suggests that more years of experience are associated with a greater attribution of masculine traits $(r=0.171, p<0.01)$.

The table below (Table 1) shows the percentages of female members in the Sports Federations considered in the study. Almost all the data were found on the web pages of the federations, while those missing were requested by contacting the federations directly by e-mail.

When the percentages exceed the threshold of 50\%, the Sports Federations are considered "female-dominated federations". Thus, the "female-dominated federations" are the Italian Gymnastics Federation (FGdI), the Italian Volleyball Federation (FIPAV), the Italian Equestrian Sports Federation (FISE) and the Italian Hockey and Skating Federation (FIHP).

A correlation has been found between the actual number of women members in Sports Federations and the responses of the coaches-those who belong to female federations marked $83 \%$ as "female", while those who belong to male-dominated federations marked $73.1 \%$ as 'male'. 
Table 1. Percentage of female members in the corresponding Sports Federations.

\begin{tabular}{cc}
\hline Federations & $\%$ Female Members \\
\hline Italian Rugby Federation (FIR) & $8.74 \%$ \\
Italian Winter Sports Federation (FISI) & $31.94 \%$ \\
Italian Cycling Federation (FCI) & $9.76 \%$ \\
Italian Gymnastic Federation (FGdI) & $87.81 \%$ \\
Italian Volleyball Federation (FIPAV) & $74.32 \%$ \\
Italian Equestrian Sports Federation (FISE) & $66.82 \%$ \\
Italian Sailing Federation (FIV) & $34.42 \%$ \\
Italian Hockey and Skating Federation (FIHP) & $62.35 \%$ \\
Italian Baseball Softball Federation (FIBS) & $21.40 \%$ \\
Italian Tennis Federation (FIT) & $33.00 \%$ \\
\hline
\end{tabular}

Coaches belonging to female-dominated Sports Federations stated that there are no forms of gender discrimination $(91.4 \%)$ in their federation, while $49.6 \%$ of those belonging to male-dominated Sports Federations answered that there is discrimination. This is a high percentage considering that only $8.6 \%$ of female coaches belonging to "female" federations stated that there is discrimination.

Regarding the scale Gender Identification at Work, the score obtained by the coaches changes depending on whether they belong to a female- or male-dominated federation $(p<0.05)$. A higher mean has been found for those participants belonging to "female" federations (5.04 vs. 4.74).

The table below (Table 2) shows the correlations between the measurement scales.

Table 2. Correlations among measurement scales: Gender Identification at Work; Bem SexRole Inventory (BSRI male and female components); Attitudes Towards Women Scale (ATWS); Macho Scale; Survey of Perceived Organizational Support (POS); Organizational Commitment Questionnaire (OrgCom).

\begin{tabular}{cccccccc}
\hline & GenderIdent & BSRI_M & BSRI_F & ATWS & MachoS & POS & OrgCom \\
\hline GenderIdent & 1 & & & & & & \\
BSRI_M & 0.078 & 1 & & & & & \\
BSRI_F & $2.223^{* *}$ & $0.124^{* *}$ & 1 & & & & \\
ATWS & -0.002 & $0.095^{*}$ & 0.049 & 1 & & & \\
MachoS & -0.025 & $0.144^{* *}$ & 0.065 & $0.600^{* *}$ & 1 & 1 & \\
POS & $0.264^{* *}$ & 0.007 & $0.167^{* *}$ & 0.041 & 0.031 & $0.529^{* *}$ & 1 \\
OrgCom & $0.258^{* *}$ & $0.175^{* *}$ & $0.200^{* *}$ & 0.055 & 0.044 & & \\
\hline
\end{tabular}

Note: ${ }^{*} p<0.05 ;{ }^{* *} p<0.01$.

A significant correlation has been found between female adjectives (BSRI_F) and Gender Identification at Work (GenderIdent; $r=0.223, p<0.01$ ), between Macho Scale scores and male adjectives (MachoS, BSRI_M; $r=0.144, p<0.01$ ), between Survey of Perceived Organizational Support scores, Gender Identification at Work (POS; $r=0.264$, $p<0.01)$ and female adjectives $(r=0.167, p<0.01)$, and between scores on the Organizational Commitment Questionnaire, Gender Identification at Work (OrgCom; $r=0.258, p<0.01$ ), male adjectives $(r=0.175, p<0.01)$ and female adjectives $(r=0.200, p<0.01)$. The strongest correlations were found between scores on the Macho Scale and the ATWS $(r=0.600$, $p<0.01)$, and between scores on the Survey of Perceived Organizational Support and the Organizational Commitment Questionnaire $(r=0.529, p<0.01)$.

\section{Discussion}

Gender-oriented behaviors occur in Sports Federations, as in other environments and organizations. For this reason, it was decided to investigate how the Queen bee phenomenon emerges within Sports Federations. A sample of female coaches from the Italian Sport Federation participated in the study voluntarily and anonymously. An online questionnaire composed of the socio-demographic questions and scales usually used 
to investigate the Queen bee syndrome and other gender-related aspects (i.e., gender stereotypes) was used.

The analyses have confirmed that female coaches in the older age groups describe themselves in a more masculine manner and attain higher scores in the Attitudes Towards Women Scale and the Macho Scale. This finding is in line with the results of a study by Ellemers et al. [2] comparing two generations of university professors in Italy. Given that the women in the older generations had started their academic career at a time in history when this was exceptional for women, it is likely that they adopted a masculine self-description and distanced themselves from other women in order to move forward in their career. The same is true in sport: the older generation of women presented themselves in a more masculine way compared to the younger generation, reporting stronger stereotypical perceptions. A possible interpretation of this result could be that the women of the older generation are women who have made successful careers in sports, and thus tend to distinguish themselves from their gender group by perceiving themselves as a non-prototypical woman [2]. As in the Ellemers' study [2], it is possible that younger female colleagues describe themselves as less masculine because they have adopted a less masculine autosterotype.

An interesting aspect that emerges from our study concerns the distribution of the sample by age group: $41.1 \%$ of the women who participated in the survey belong to the 18-29 age group, while only $7.8 \%$ are over 50 . However, it must be considered that in our study, women over 50 years old work as female coaches as a second job, and they report having a family. In contrast, younger women who do not have families are more likely to be dedicated to their coaching jobs. This finding is in line with the evidence from two studies. A recent study showing that women executives in sport institutions report multiple factors, specifically binary workloads, physical fatigue, time-saving, responsibility for children, etc., as barriers to their careers. In addition, the identity of sports organizations is also perceived by women as a barrier to their careers [45]. Another study shows that women coaches tend to be younger, unmarried, less likely to have children, only hold part time positions, etc. [33].

A correlation was found between the actual number of women members in Sports Federations and the responses of the coaches, showing that there is consistency between the real number and the perceived one. This indicates that women within federations recognize whether a federation is made up of more women or men, and this matters to them.

As expected, female coaches from Sports Federations with more male members reported more gender discrimination than female-dominated federations. In fact, in this case, women find it easier to find a female role model to follow and are not forced to adopt stereotypically masculine behavior, which happens in sexist organizational federations.

Coaches belonging to female-dominated Sport Federations attained a higher score in the Gender Identification at Work scale; this result confirms the hypothesis that coaches belonging to "female" federations identify themselves more with other women in the workplace, compared to coaches belonging to male-dominated federations.

Significant correlations were found between female adjectives and Gender Identification at Work, between Macho Scale scores and male adjectives, between Survey of Perceived Organizational Support scores, Gender Identification at Work and female adjectives, and between Organizational Commitment Questionnaire scores, Gender Identification at Work, male adjectives and female adjectives. The strongest correlations were found between the scores obtained on the Macho Scale and the ATWS, and between the scores of the Survey of Perceived Organizational Support and the Organizational Commitment Questionnaire, both of which confirm a trend already present in the literature [46-49].

The hypotheses concerning the presence of an association between membership in a women's federation and the scales Survey of Perceived Organizational Support and Organizational Commitment Questionnaire were not confirmed by the analyses. As such, the score obtained on these two scales does not change depending on the type of federation to which the coaches belong to (whether "male" or "female" federations). 
We hope that this study will represent the first step towards a deeper understanding of the Queen bee phenomenon within the sport environment.

\section{Conclusions}

Despite its limitations, the present study opens up the possibility that the phenomenon of the Queen bee syndrome is present within the Italian Sports Federations. The data of our study are related to the Italian socio-cultural context, and so it would be interesting to expand this research to coaches of different nationalities to see how this phenomenon can change; for example, by analyzing whether countries where there are more women at the tops of federations show different impacts on the variables analyzed. Our study is limited to quantitative data collection, but in order to improve the understanding of the phenomenon of the Queen bee syndrome within the sporting environment, it would be advisable to use a multifaceted method, using also qualitative data collection, such as via interviews [39].

In future research, it would be interesting to evaluate additional variables involved in the Queen bee phenomenon and to continue to investigate the world of sport, as it is immersed in an ever-changing culture thanks to the efforts of multiple figures who struggle to make it as gender-equal as possible. Moreover, it would be interesting to investigate whether the Queen bee syndrome changes according to the type of sport practiced, be it individual or team.

From an application point of view, programs could be implemented to raise awareness among the younger generations through, for example, the testimony of athletes who are part of the organizational leadership, or who have become coaches, in order to convey the message that everyone has the same opportunity to go down that road regardless of gender, and emphasizing the richness that diversity gives us. In this way, through testimonial and mentoring programs, it would be possible to help boys and girls choose to work within federations in decision-making positions.

Author Contributions: Conceptualization, C.C. and I.L.; methodology, C.C. and I.L.; analysis, C.C. and I.L.; writing-original draft preparation C.C. and I.L.; writing-review and editing C.C. and I.L. All authors have read and agreed to the published version of the manuscript.

Funding: This research received no external funding.

Institutional Review Board Statement: This study was conducted in accordance with the Declaration of Helsinki.

Informed Consent Statement: Informed consent was obtained from all subjects involved in the study. Data Availability Statement: Not applicable.

Conflicts of Interest: The authors declare that the research was conducted in the absence of any commercial or financial relationships that could be construed as a potential conflict of interest.

\section{References}

1. Gibson, D.E.; Cordova, D.I. Women's and Men'S Role Models: The Importance of Exemplars. In Mentoring Dilemmas; Murress, A.J., Crosby, F.J., Ely, R.J., Eds.; Lawrence Erlbaum Associates, Inc.: Mahwah, NJ, USA, 1999; pp. 121-142.

2. Ellemers, N.; van den Heuvel, H.; de Gilder, D.; Maass, A.; Bonvini, A. The underrepresentation of women in science: Differential commitment or the queen bee syndrome? Br. J. Soc. Psychol. 2004, 43, 315-338. [CrossRef] [PubMed]

3. Tavris, C.; Staines, G.; Jayaratne, T.E. The queen bee syndrome. Psychol. Today 1973, 7, 63-66.

4. Ellemers, N. Individual Upward Mobility and the Perceived Legitimacy of Intergroup Relations. In The Psychology of Legitimacy; Jost, J.T., Major, B., Eds.; Cambridge University Press: Cambridge, UK, 2001.

5. Tajfel, H.; Turner, J.C. The Social Identity Theory of Intergroup Behavior. In The Psychology of Intergroup Relations; Worchel, S., Austin, W.G., Eds.; Nelson-Hall: Boston, MA, USA, 1986; pp. 7-24.

6. Nedelmann, B. Ruoli maschili e Femminili. Enciclopedia delle Scienze Sociali. Available online: https://www.treccani.it/ enciclopedia/ruoli-maschili-e-femminili_\%28Enciclopedia-delle-scienze-sociali\%29/ (accessed on 15 December 2021).

7. Eagly, A.H.; Wood, W.; Diekman, A.B. Social Role Theory of Sex Differences and Similarities: A Current Appraisal. In The Developmental Social Psychology of Gender; Eckes, T., Trauther, H.M., Eds.; Lawrence Erlbaum Associates, Inc.: Mahwah, NJ, USA, 2000; pp. 123-160. 
8. Diekman, A.B.; Eagly, A.H.; Kulesa, P. Accuracy and Bias in Stereotypes about the Social and Political Attitudes of Women and Men. J. Exp. Soc. Psychol. 2002, 38, 268-282. [CrossRef]

9. Eagly, A.H.; Steffen, V.J. Gender Stereotypes Stem From The Distribution of Women and Men into Social Roles. J. Pers. Soc. Psychol. 2000, 1, 735-754.

10. Eisenberger, R.; Fasolo, E.M.; Davis-LaMastro, V. Effects of perceived organizational support on employee diligence, innovation, and commitment. J. Appl. Psychol. 1990, 53, 51-59. [CrossRef]

11. Charles, N.; Davies, C.A. Cultural stereotypes and the gendering of senior management. Sociol. Rev. 2000, 12, 544-567. [CrossRef]

12. Battistelli, A.; Mariani, M.G. Perceived Organizational Support: Validation of the Italian version of the Survey of Perceived Organizational Support (with eight items). Giornale Italiano di Psicologia 2011, 38, 189-214.

13. Volpato, C. Psicosociologia del Maschilismo; Gius.Laterza \& Figli Spa.: Bari, Italy, 2013.

14. Campus, D. Women Political Leaders and the Media; Palgrave MacMillan: London, UK, 2013.

15. Rudman, L.A. Self-promotion as a risk factor for women: The costs and benefits of counter-stereotypical impression management. J. Pers. Soc. Psychol. 1998, 74, 629-645. [CrossRef] [PubMed]

16. Heilman, M.E.; Wallen, A.S.; Fuchs, D.; Tamkins, M.M. Penalties for success: Reactions to women who succeed at male gender-typed tasks. J. Appl. Psychol. 2004, 89, 416-427. [CrossRef]

17. Marshall, J. Researching women and leadership: Some comments on challenges and opportunities. Int. Rev. Women Leadersh. 1995, 1, 1-10.

18. Wacjman, J. Managing Like a Man; Blackwell: Oxford, UK, 1998.

19. Branscombe, N.R.; Ellemers, N.; Spears, R.; Doosje, B. The Context and Content of Social Identity Threat. In Social Identity: Context, Commitment, Content; Ellemers, N., Spears, R., Doosje, B., Eds.; Blackwell: Oxford, UK, 1999; pp. 35-58.

20. Derks, B.; Van Laar, C.; Ellemers, N. The queen bee phenomenon: Why women leaders distance themselves from junior women. Leadersh. Q. 2016, 27, 456-469. [CrossRef]

21. Derks, B.; Van Laar, C.; Ellemers, N. Working for the self or working for the group: How self-versus group affirmation affects collective behavior in low-status groups. J. Pers. Soc. Psychol. 2009, 96, 183. [CrossRef] [PubMed]

22. Ellemers, N.; Spears, R.; Doosje, B. Sticking together of falling apart: In-group identification as a psychological determinant of group commitment versus individual mobility. J. Pers. Soc. Psychol. 1997, 72, 617-626. [CrossRef]

23. Ely, R.J. The power in demography: Women's social constructions of gender identity at work. Acad. Manag. Ann. 1994, 38, 589-634.

24. Hargreaves, J. Sporting Females: Critical Issue in the History and Sociology of Women's Sport; Routledge: London, UK, 1994.

25. Volpicelli, L. Industrialismo e Sport; Armando Editore: Roma, Italy, 1966.

26. Murphy, P. Sport and Gender. In A Sociological Perspective on Sport; Wilbert, M.L., Ed.; Palgrave Macmillan: London, UK, 1988.

27. Christensen, K.; Guttmann, A.; Pfister, G. International Encyclopedia of Women and Sports; Christensen, K., Guttmann, A., Pfister, G., Eds.; Macmillan Publishers: New York, NY, USA, 2001.

28. Sassatelli, R. Lo Sport al Femminile Nella Società Moderna. Available online: https://www.treccani.it/enciclopedia/lo-sport-alfemminile-nella-societa-moderna_(Enciclopedia-dello-Sport)/ (accessed on 15 December 2021).

29. Blom, L.; Abrell, L.K.; Wilson, M.; Lape, J.E.; Halbrook, M.; Judge, L. Working with Male Athletes: The experiences of U.S. Feamle Head Coaches. ICHPER-SD J. Res. 2011, 6, 54-61.

30. Pfister, G. Gender Equality And (Elite) Sport. A Report. Available online: https://www.researchgate.net/profile/DennisMazur-2/post/Is_anyone_researching_sexual_liberation_and_womens_oppression/attachment/59d6581d79197b80779ae2 98/AS\%3A537190648250368\%401505087639898/download/INF25+Gender+equality+and+elite+sport.pdf (accessed on 15 December 2021).

31. Kanter, R.M. Men and Women of the Corporation; Basic Books: New York, NY, USA, 1977.

32. Kerr, G.; Banwell, J. Striving for gender equity in coaching Female athletes' perspectives on pursuing coaching as a career. Can. J. Women Coach. 2014, 14, 1-7.

33. Reade, I.; Rodgers, W.; Norman, L. The under-representation of women in coaching: A comparison of male and female Canadian coaches at low and high levels of coaching. Int. J. Sports Sci. 2009, 4, 505-520. [CrossRef]

34. Yiamouyiannis, A. Occupational Closure in Intercollegiate Athletics: Female Head Coaches of Men'S Sport Teams at NCAA Colleges. Ph.D. Dissertation, The George Washington University, Washington, DC, USA, 2008.

35. Talbot, M. Gender, Power and Culture. A Centenary Celebration of Women in the Olympics; Meyer \& Meyer Sport: Aachen, Germany, 2001.

36. Schoch, L.; Clausen, J. Women within International Sports Federations: Contemporary Challenges. In A Man's World? A History of Women and Leadership in Sport; Palgrave Macmillan: London, UK, 2019.

37. Crepaz, P. All You Need is Sport. Agonismo Sociale e Felicità Inclusiva; Erickson edizioni: Trento, Italy, 2019.

38. Derks, B.; Van Laar, C.; Ellemers, N.; de Groot, K. Gender-Bias Primes Elicit Queen-Bee Responses Among Senior Policewomen. Psychol. Sci. 2011, 22, 1243-1249. [CrossRef] [PubMed]

39. Şengül, H.; Çınar, F.; Bulut, A. The perception of queen bee phenomenon in nurses; qualitative study in health sector. Niger J. Clin. Pract. 2019, 22, 906-912. [CrossRef]

40. Bem, S.L. Bem Sex-Role Inventory: Professional Manual; Consulting Psychologists Press: Palo Alto, CA, USA, 1981.

41. Spence, J.T.; Helmreich, R.; Stapp, J. A short version of the Attitudes toward Women Scale (AWS). Bull. Psychon. Rev. 1978, 2, 219-220. [CrossRef] 
42. Villemez, W.J.; Touhey, J.C. A measure of individual differences in sex stereotyping and sex discrimination: The Macho Scale. Psychol. Rep. 1977, 41, 411-415. [CrossRef]

43. Eisenberger, R.; Huntington, R.; Hutchison, S.; Sowa, D. Perceived organizational support. J. Appl. Psychol. 1986, 71, 500-507. [CrossRef]

44. Allen, N.J.; Meyer, J.P. The measurement and antecedents of affective, continuance and normative commitment to the organization. J. Occup. Psychol. 1990, 63, 1-18. [CrossRef]

45. Kara, F.M.; Çolakoğlu, T.; Erturan Ogut, E.E. Career Barriers of Women Managers in Sports Organizations. Int. J. Sports Exerc. Train. Sci. 2016, 2, 82-92. [CrossRef]

46. Gayton, W.F.; Sawyer, B.L.; Baird, J.G.; Ozmon, K.L. Further validation of a new measure of machismo. Psychol. Rep. 1982, 51, 820-822. [CrossRef]

47. Sattem, L.; Savells, J.; Murray, E. Sex-role stereotypes and commitment of rape. Sex Roles 1984, 11, 849-860. [CrossRef]

48. Meyer, J.P.; Allen, N.J. Commitment in the Workplace; Sage: London, UK, 1997.

49. Meyer, J.P.; Stanley, D.J.; Herscovitch, L.; Topolny, L. Affective, Continuance and Normative Commitment to the Organization: A Meta-analysis of Antecedents, Correlates and Consequences. J. Vocat. Behav. 2002, 61, 20-52. [CrossRef] 